\title{
AN EMPIRICAL STUDY ON THE IMPACT FROM THE ANTECEDENTS OF PERSON ORGANISATION FIT AFFECTING A WRIST WATCH MANUFACTURING UNIT IN TAMIL NADU
}

\author{
J. Praveen Paul ${ }^{1}$ and M. Silambarasan ${ }^{2}$ \\ Department of Management Studies, Mepco Schlenk Engineering College, India
}

\begin{abstract}
This paper presents and tests a theoretical model of personorganization (P-O) fit and its antecedents among 243 employees working in a wrist watch manufacturing unit in Tamil Nadu. The interaction of the variables of $P-O$ fit were analysed for the different demographics of employees who were grouped based on their gender, age, designation, educational qualification and work experience in the current organisation. Multiple linear regressions (MLR) were carried out for the different demographics of employees separately with all the antecedents together on the overall perception of $P$-O fit. Subsequently, to find the impact of the individual antecedents of $P$-O fit individually, simple linear regressions (SLR) were carried out and the results were compiled together. It was found that the impact of the antecedents on the P-O fit differs with the different employee demographics.
\end{abstract}

\section{Keywords:}

Person-Organisation Fit, Congruence, Principles, Values and Norms, Work Mates, Need, Ability, Education and Personal skill, Culture, Personality, Goal, Work Place

\section{INTRODUCTION AND REVIEW}

It is a well-known fact that people who find themselves fitting into a particular organizational environment achieve higher levels of career success in their professional lives and generally will be more satisfied with their jobs and personal lives than those who do not. Measuring this person - organisation fit (P-O Fit) becomes imperative in any organisation. Empirical research establishes that P-O fit results in positive work related outcomes [1] [2] [3]. Theoretical and related empirical research shows that individuals (employees) will seek out, find comfort, and flourish in environments that support their specific preferences.

Early theories of P-O fit were aimed primarily at recruitment and selection. The selection was aimed at employing people with adequate qualifications and committed to the performed job. The criteria of matching the person with the job were also supposed to help to employ satisfied and efficient workers. However P-O fit could also be used as a tool for finding out if a person will fit in an organisation after a period of time. P-O fit in an organization is related to factors such as job performance, [4], work attitude [5], turnover [6], teamwork effectiveness [7], organizational citizenship behaviours [8], [9], creativity [10] stress and wellbeing [11].

The most common way of conceptualizing P-O fit are goals [12], compatibility between the employee's perception of his/her workplace [13], organisation norms [14], work values, abilities to meet organizational demands, employee needs [15], organisation culture [3], Individuals being successful in organizations that share their personalities [16], opportunity to work without giving up my personal principles [17], workmates exhibit similar behaviour, the employees' education and personal skills about job are compatible with the organisation [18].

Researchers broadly define P-0 fit as the compatibility between individuals and organizations [15]. This Compatibility is conceptualized in a variety of ways. The most common conceptualisation of $\mathrm{P}-\mathrm{O}$ fit is value congruence which indicates the similarity in values between the organisation and the individual working in that organisation [19]. The first distinction is between supplementary and complementary fit.

Supplementary fit occurs when a person "supplements, embellishes, or possesses characteristics which are similar to other individuals" in an environment [20]. This is value congruence. Value congruence can be differentiated from complementary fit, which occurs when a person's characteristics "make whole" the environment or add to it what is missing [20].

Individuals tend to be more attracted to organisations that they perceive having similar values to them and individuals who do not share the same values with their organisations tend to be less satisfied and less committed to their organisation [21]. Organisational environment can provide opportunity to fulfil their needs which in turn results in positive work attitudes [22].

Operationalization of P-0 Fit: The most frequently used operationalization of this perspective on fit is the congruence between individual and organizational values [23] [14] [24] [25].

Person's fit with the organization (P-O fit) associates a person's personality, goals and values with those of the organization. The Person-organization fit essentially argues that people are attracted to and selected by organizations that match their values, and they leave organizations that are not compatible with their personalities [26].

Reducing employee turnover is a strategy that has significant relation in the degree of fit between a person and the organization. The importance of $\mathrm{P}-\mathrm{O}$ fit for organizations is indicated by significant relationships between $\mathrm{P}-\mathrm{O}$ fit and turnover [27].

When the team activities had a good "fit" with other organizational activities then performance is enhanced and resistance to change is reduced [28].

There are ten ways in managing the person-organization fit effectively to ensure that the organization gain the objectives in term of organizational objectives such as employee turnover, profitability, sustainability, market leadership as well as individual and or organization's member objectives such as having meaningful work, appreciation, career, well-being, good human relationship at work and quality of life: 1) Process of hire and selection of employees; 2) Deliver communication/message during hire and selection of employee; 3) Socialization(new employees getting adapted to the organization culture); 4) Intervening culture; 5) Comprehensive training; 6) Measure 
"ideal" and "actual" of organization culture and values; 7) Career development management process; 8) Maintain diversity in the organization; 9) The role of the leader; and 10) Focus on both the individual and the organization culture [29], [30], [31].

In a recent study the researchers examines the unique relationships of Person-Organisation fit and person-job (P-J) fit. Hierarchical multiple regression was used to test the hypotheses. The research concluded that P-O fit and P-J fit influences job satisfaction and organisational commitment [32]. Dorota and Andysz analysed fifteen socio-demographic variables and work characteristics that could impact $\mathrm{P}-\mathrm{O}$ fit and found that only a few were significantly associated with $\mathrm{P}-\mathrm{O}$ fit such as social relationships, time demands, work shifts schedule systems, depression, health and functioning, employment history etc. They also found that demographic variables in general were not an important predictor of good P-O fit for both the genders [33].

\section{METHODOLOGY}

The objective of this study was to identify the impact of the antecedents of person-organization fit of the employees in a wrist watch manufacturing unit based in the Hosur district of Tamil Nadu. The research is confined to Hosur branch employees and does not necessarily shows a pattern applicable to the all of country. Some respondents were reluctant to divulge personal information which can affect the validity of all responses. Approaching the superiors is found to be difficult in the earlier stages of data collection.

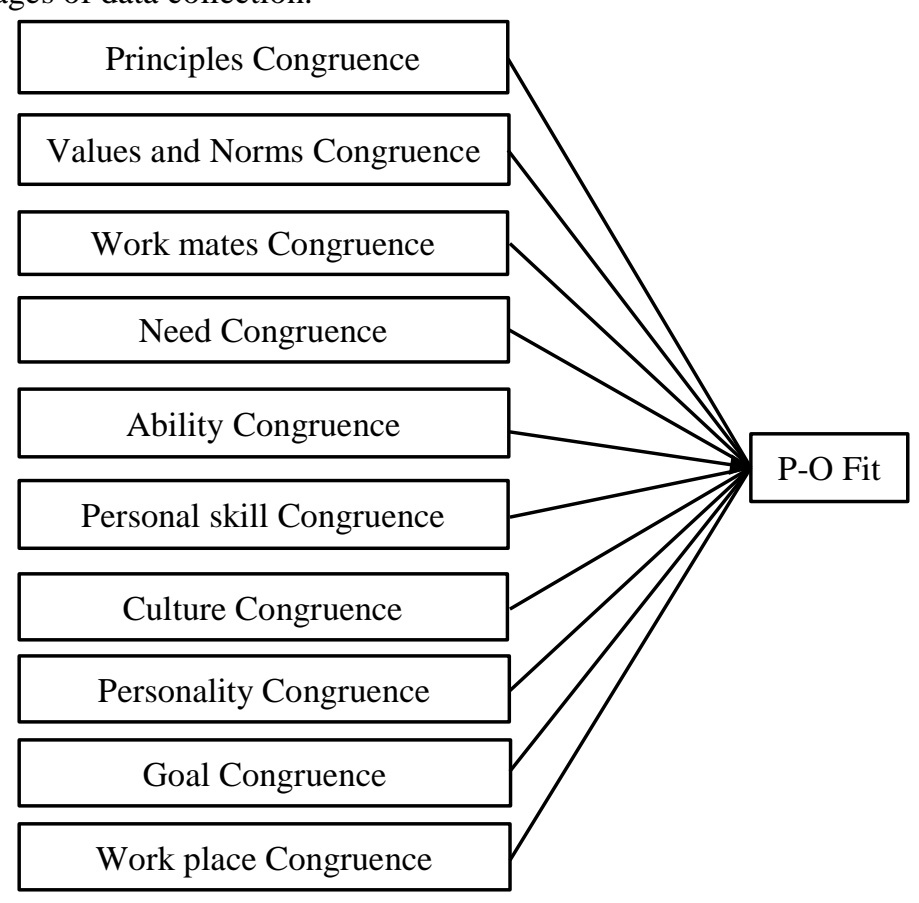

Fig.1. Antecedents of P-O fit

\subsection{RESEARCH DESIGN}

The research method of this study is causal study. This study is conducted in order to identify the extent of the cause and effect relationship among the dependent and independent variable. The objective is to determine whether the person is fit for the organization survey is conducted from employees at the wrist watch unit. The nature of data used for this research is both Primary data and Secondary data. Primary data was collected from the respondents by a direct interview using structured questionnaire with five point Likert scale.

\subsection{SAMPLING DESIGN}

In this research, from the population of 653 employees, a sample of 243 employees was chosen through probabilistic sampling method of simple random sampling. The variables were identified from the literature. The antecedents considered for measuring P-O fit are listed below in Table.1. The codes A1 to A10 will be used to indicate the antecedents in the following discussions. The dependent variable was measured using the employees' opinion on their perception on their fit with their organisation.

Table.1. Antecedents Considered for P-O fit

\begin{tabular}{|c|c|}
\hline A1 & $\begin{array}{c}\text { I have opportunity to work without giving up my } \\
\text { personal principles in this organisation }\end{array}$ \\
\hline A2 & $\begin{array}{c}\text { My work values are compatible with that of my } \\
\text { organisation values \& norms }\end{array}$ \\
\hline A3 & $\begin{array}{c}\text { A lot of workmates exhibit similar behaviour related to } \\
\text { the work in this organisation }\end{array}$ \\
\hline A4 & $\begin{array}{c}\text { Me and my organisation complement one another by } \\
\text { addressing each other's needs }\end{array}$ \\
\hline A5 & I have the abilities that meets organizational demands \\
\hline A6 & $\begin{array}{c}\text { My education and personal skills about job are } \\
\text { compatible with the needs of my organisation. }\end{array}$ \\
\hline A7 & My Organisation's culture is similar to that of mine \\
\hline A8 & $\begin{array}{c}\text { I am successful because my personality matches with my } \\
\text { organisation }\end{array}$ \\
\hline A9 & My goals and organization goals are in congruence \\
\hline A10 & $\begin{array}{c}\text { There is compatibility between my perception of } \\
\text { workplace and reality. }\end{array}$ \\
\hline
\end{tabular}

\section{DESCRIPTION OF DATA}

The researchers collected the information about the demographics of the two hundred and forty three employees in the watch manufacturing unit and their demographics is presented in Table.2.

Table.2. Description of employees based on various factors

\begin{tabular}{|c|c|c|}
\hline Factors & Particulars & No. of. Respondent \\
\hline \multirow{2}{*}{ Gender } & Male & 174 \\
\cline { 2 - 3 } & Female & 69 \\
\hline \multirow{3}{*}{ Age } & $20-30$ & 108 \\
\cline { 2 - 3 } & $31-40$ & 129 \\
\cline { 2 - 3 } & 41 and above & 06 \\
\hline \multirow{2}{*}{ Designation } & Managers & 25 \\
\cline { 2 - 3 } & Non Managers & 218 \\
\hline Education & ITI & 87 \\
\hline
\end{tabular}




\begin{tabular}{|c|c|c|}
\hline \multirow{4}{*}{} & Polytechnic & 84 \\
\cline { 2 - 3 } & $\mathrm{UG}$ & 56 \\
\cline { 2 - 3 } Experience & $\mathrm{PG}$ & 16 \\
\hline & $1-10$ years & 156 \\
\cline { 2 - 3 } & $11-20$ years & 85 \\
\cline { 2 - 3 } & $21-25$ years & 02 \\
\hline
\end{tabular}

While observing the profile of the employees, it can be seen that the manufacturing unit has predominantly male employees. Most of the employees are within forty years of age. Also most of the employees have an experience within twenty years. The Table. 3 exhibits lesser standard deviation and the mean scores indicate a positive response.

Table.3. Mean and Standard Deviation values for the antecedents of P-O fit

\begin{tabular}{|c|c|c|}
\hline Factors & $\bar{x}$ & $\sigma$ \\
\hline $\begin{array}{l}\text { I have opportunity to work without giving up } \\
\text { my personal principles in this organisation }\end{array}$ & 3.70 & 0.63 \\
\hline $\begin{array}{l}\text { My work values are compatible with that of } \\
\text { my organisation values \& norms }\end{array}$ & 3.96 & 0.97 \\
\hline $\begin{array}{l}\text { A lot of workmates exhibit similar behaviour } \\
\text { related to the work in this organisation }\end{array}$ & 3.36 & 1.32 \\
\hline $\begin{array}{l}\text { Me and my organisation complement one } \\
\text { another by addressing each other's needs }\end{array}$ & 3.51 & 0.98 \\
\hline $\begin{array}{l}\text { I have the abilities that meets organizational } \\
\text { demands }\end{array}$ & 3.63 & 1.11 \\
\hline $\begin{array}{l}\text { My education and personal skills about job } \\
\text { are compatible with the needs of my } \\
\text { organisation. }\end{array}$ & 3.65 & 1.15 \\
\hline $\begin{array}{c}\text { My Organisation's culture is similar to that } \\
\text { of mine }\end{array}$ & 3.65 & 1.04 \\
\hline $\begin{array}{l}\text { I am successful because my personality } \\
\text { matches with my organisation }\end{array}$ & 3.44 & 1.00 \\
\hline $\begin{array}{l}\text { My goals and organization goals are in } \\
\text { congruence }\end{array}$ & 3.46 & 0.98 \\
\hline $\begin{array}{l}\text { There is compatibility between my } \\
\text { perception of workplace and reality. }\end{array}$ & 3.26 & 0.82 \\
\hline
\end{tabular}

\section{ANALYSIS}

For finding the impact of all the antecedents of P-O fit together on overall feeling of an employee's fit in the organisation, a multiple linear regression (MLR) [32] was done and the results were analysed. Further, to find the impact of the various antecedents individually on the PO fit of the employees, simple linear regressions were done individually and the outcomes were consolidated in a single table.

\subsection{IMPACT OF FACTORS INFLUENCING P-O FIT ON ALL EMPLOYEES}

In this section, the impact of the various antecedents for $\mathrm{P}-\mathrm{O}$ fit was considered together and the results of the MLR are tabulated in Table.4. The Table.5 presents the coefficients of the regression which is used to formulate the regression between the
IV and DV. The Table.6 presents the impact of the individual factors influencing the P-O fit of all employees separately. The values in this Table. 4 are a consolidation of separate simple linear regressions done separately and compiled together.

Table.4. Impact of all antecedents influencing P-O fit for all employees using MLR

\begin{tabular}{|c|c|c|c|c|c|}
\hline \multirow{2}{*}{ Variables } & \multirow{2}{*}{$\mathbf{R}$} & \multirow{2}{*}{ Adj $\mathbf{R}^{\mathbf{2}}$} & \multicolumn{3}{|c|}{ Change Statistics } \\
\cline { 4 - 6 } & & & $\mathbf{R}^{\mathbf{2}}$ & $\mathbf{F}$ & Sig. \\
\hline All Variables & 0.822 & 0.662 & 0.676 & 48.477 & .000 \\
\hline
\end{tabular}

Table.5. Coefficients of the MLR for all employees

\begin{tabular}{|c|c|c|c|}
\hline Factors & $\boldsymbol{\beta}$ & $\mathbf{t}$ & Sig. \\
\hline (Constant) & -0.250 & -.873 & .384 \\
\hline A1 & 0.186 & 4.597 & .000 \\
\hline A2 & 0.219 & 5.358 & .000 \\
\hline A3 & 0.360 & 9.141 & .000 \\
\hline A4 & 0.287 & 7.388 & .000 \\
\hline A5 & 0.259 & 6.663 & .000 \\
\hline A6 & 0.296 & 7.704 & .000 \\
\hline A7 & 0.283 & 7.365 & .000 \\
\hline A8 & 0.268 & 6.983 & .000 \\
\hline A9 & 0.265 & 6.486 & .000 \\
\hline A10 & 0.267 & 6.771 & .000 \\
\hline
\end{tabular}

The results in Table. 4 shows that $p<0.05$ which indicates that, overall, the regression model predicts the outcome variable both statistically and significantly. The $R$ value indicates a high degree of correlation. The $R^{2}$ value indicates that $67.6 \%$ of the total variation in the dependent variable can be explained by the independent variable. The $R^{2}$ value may be considered to be sufficiently large. The regression equation formed from the coefficients presented in Table. 5 is as follows:

$$
\begin{aligned}
\mathrm{Y}= & -0.25+0.186 \beta_{1}+0.219 \beta_{2}+0.360 \beta_{3}+0.287 \beta_{4}+0.259 \beta_{5}+ \\
& 0.296 \beta_{6}+0.283 \beta_{7}+0.268 \beta_{8}+0.265 \beta_{9}+0.267 \beta_{10}
\end{aligned}
$$

where,

$Y$ is the overall feeling of an employee's fit in the organisation

$\beta_{1}$ is the Principles Congruence

$\beta_{2}$ is the Values and Norms Congruence

$\beta_{3}$ is the Work mates Congruence

$\beta_{4}$ is the Need Congruence

$\beta_{5}$ is the Ability Congruence

$\beta_{6}$ is the Personal skill Congruence

$\beta_{7}$ is the Culture Congruence

$\beta_{8}$ is the Personality Congruence

$\beta_{9}$ is the Goal Congruence

$\beta_{10}$ is the Work place Congruence

Since, the same variables are considered in the subsequent regressions, the nomenclature for $Y$ and $\beta$ is the same and hence the nomenclature is not repeated. 
Table.6. Impact of individual factors influencing P-O fit of all employees using SLR

\begin{tabular}{|c|c|c|c|c|c|c|c|}
\hline \multirow{2}{*}{ Variables } & \multirow{2}{*}{$\mathbf{R}$} & \multirow{2}{*}{$\operatorname{Adj} R^{2}$} & \multirow[b]{2}{*}{$\mathbf{t}$} & \multirow{2}{*}{$\begin{array}{l}\text { Reg } \\
\text { coeff }\end{array}$} & \multicolumn{3}{|c|}{ Change Statistics } \\
\hline & & & & & $\mathbf{R}^{2}$ & $\mathbf{F}$ & Sig. \\
\hline $\mathrm{A} 2$ & 0.184 & 0.030 & 2.901 & 0.105 & 0.034 & 8.418 & .004 \\
\hline A3 & 0.389 & 0.148 & 6.559 & 0.165 & 0.151 & 43.020 & .000 \\
\hline A4 & 0.257 & 0.062 & 4.130 & 0.146 & 0.066 & 17.053 & .000 \\
\hline A5 & 0.204 & 0.038 & 3.235 & 0.102 & 0.042 & 10.463 & .001 \\
\hline A6 & 0.232 & 0.050 & 3.704 & 0.113 & 0.054 & 13.720 & .000 \\
\hline A7 & 0.286 & 0.078 & 4.641 & 0.154 & 0.082 & 21.541 & .000 \\
\hline A8 & 0.282 & 0.076 & 4.557 & 0.157 & 0.079 & 20.767 & .000 \\
\hline A9 & 0.276 & 0.072 & 4.462 & 0.157 & 0.076 & 19.913 & .000 \\
\hline A10 & 0.275 & 0.072 & 4.437 & 0.186 & 0.076 & 19.683 & .000 \\
\hline
\end{tabular}

The regression outcomes in Table. 6 show that all the antecedents of P-O fit except Principles Congruence have a significant impact on the P-O fit of all the categories of employees. The regression equations for each factor will be in the form of $\mathrm{Y}=a+\beta x$, where $Y$ is the overall feeling of an employee's fit in the organisation and $\beta$ is the regression coefficient of the respective antecedent and $\mathrm{x}$ is the antecedent of $\mathrm{P}-\mathrm{O}$ fit.

\subsection{IMPACT OF FACTORS INFLUENCING P-O FIT - BY GENDER}

In the following section, the impact of the antecedents of $\mathrm{P}-\mathrm{O}$ fit on the female and male employees were identified separately. The Table.7, Table. 8 and Table. 9 present the outcomes of female employees and Table.9, Table.10 and Table.11 present the outcomes of male employees.

Table.7. Impact of all antecedents influencing P-O fit for female employees using MLR

\begin{tabular}{|c|c|c|c|c|c|}
\hline \multirow{2}{*}{ Variables } & \multirow{2}{*}{$\mathbf{R}$} & \multirow{2}{*}{ Adj $\mathbf{R}^{2}$} & \multicolumn{3}{|c|}{ Change Statistics } \\
\cline { 4 - 6 } & & & $\mathbf{R}^{\mathbf{2}}$ & $\mathbf{F}$ & Sig. \\
\hline All Variables & 0.859 & 0.692 & 0.738 & 16.310 & .000 \\
\hline
\end{tabular}

The regression significance in Table. 7 shows that $p<0.05$ which indicates that the regression model is fit. The $R$ value indicates a high degree of correlation. The $R^{2}$ value indicates that $73.8 \%$ of the total variation in the dependent variable can be explained by the independent variable. The $R^{2}$ is sufficiently large.

Table.8. Coefficients of the MLR for female employees

\begin{tabular}{|c|c|c|c|}
\hline Factors & $\boldsymbol{\beta}$ & $\mathbf{t}$ & Sig. \\
\hline (Constant) & -0.303 & -0.626 & .534 \\
\hline A1 & 0.212 & 2.878 & .006 \\
\hline A2 & 0.336 & 4.226 & .000 \\
\hline A3 & 0.358 & 4.931 & .000 \\
\hline A4 & 0.329 & 4.593 & .000 \\
\hline A5 & 0.223 & 3.116 & .003 \\
\hline A6 & 0.279 & 3.803 & .000 \\
\hline A7 & 0.279 & 3.863 & .000 \\
\hline
\end{tabular}

\begin{tabular}{|c|c|c|c|}
\hline Factors & $\boldsymbol{\beta}$ & $\mathbf{t}$ & Sig. \\
\hline A8 & 0.213 & 2.969 & .004 \\
\hline A9 & 0.214 & 2.585 & .012 \\
\hline A10 & 0.302 & 4.171 & .000 \\
\hline
\end{tabular}

The regression equation formed from the coefficients presented in Table. 8 is as follows:

$$
\begin{aligned}
\mathrm{Y} & =-0.303+0.212 \beta_{1}+0.336 \beta_{2}+0.358 \beta_{3}+0.329 \beta_{4}+0.223 \beta_{5} \\
& +0.279 \beta_{6}+0.279 \beta_{7}+0.213 \beta_{8}+0.214 \beta_{9}+0.302 \beta_{10}
\end{aligned}
$$

Table.9. Impact of individual factors influencing P-O fit of female employees using SLR

\begin{tabular}{|c|c|c|c|c|c|c|c|}
\hline \multirow{2}{*}{ Variables } & \multirow{2}{*}{$\mathbf{R}$} & \multirow{2}{*}{$\begin{array}{c}\text { Adj } \\
\mathbf{R}^{\mathbf{2}}\end{array}$} & $\mathbf{t}$ & \multirow{2}{*}{$\begin{array}{c}\text { Reg } \\
\text { coeff }\end{array}$} & \multicolumn{2}{|c|}{ Change Statistics } \\
\cline { 6 - 9 } & & $\mathbf{R}^{\mathbf{2}}$ & $\mathbf{F}$ & Sig. \\
\hline A2 & 0.256 & 0.051 & 2.165 & .0143 & 0.065 & 4.689 & .034 \\
\hline A3 & 0.423 & 0.167 & 3.826 & 0.188 & 0.179 & 14.640 & .000 \\
\hline A4 & 0.292 & 0.072 & 2.501 & 0.166 & 0.085 & 6.253 & .015 \\
\hline A6 & 0.271 & 0.059 & 2.301 & 0.132 & 0.073 & 5.295 & .025 \\
\hline A7 & 0.251 & 0.049 & 2.124 & 0.118 & 0.063 & 4.511 & .037 \\
\hline A8 & 0.277 & 0.063 & 2.362 & 0.144 & 0.077 & 5.579 & .021 \\
\hline A9 & 0.357 & 0.115 & 3.132 & 0.213 & 0.128 & 9.807 & .003 \\
\hline A10 & 0.302 & 0.078 & 2.596 & 0.209 & 0.091 & 6.741 & .012 \\
\hline
\end{tabular}

The regressions of the individual antecedents of $\mathrm{P}-\mathrm{O}$ fit for the female employees alone are shown in Table.9. Here, all the antecedents of $\mathrm{P}-\mathrm{O}$ fit except Principles congruence and ability congruence have a significant impact on the $\mathrm{P}-\mathrm{O}$ fit of all the categories of employees. Observing the values presented in the Table.10 it can be seen that even though the variables like value and norms congruence, need congruence, personal skills congruence, culture congruence, personality congruence, work place congruence are significant at $p<0.05$, their correlation values and $R^{2}$ values are quite low. This indicates that these factors are not so important for females' P-O fit. The regression equations for each factor will be in the form of $\mathrm{Y}=a+\beta x$, where $Y$ is the overall feeling of female employee's fit in the organisation and $\beta$ is the regression coefficient of the respective antecedent and $x$ is the antecedent of $\mathrm{P}-\mathrm{O}$ fit.

Table.10. Impact of all antecedents influencing P-O fit for male employees using MLR

\begin{tabular}{|c|c|c|c|c|c|}
\hline \multirow{2}{*}{ Variables } & \multirow{2}{*}{$\mathbf{R}$} & \multirow{2}{*}{ Adj $\mathbf{R}^{\mathbf{2}}$} & \multicolumn{3}{|c|}{ Change Statistics } \\
\cline { 4 - 6 } & & & $\mathbf{R}^{\mathbf{2}}$ & $\mathbf{F}$ & Sig. \\
\hline All Variables & 0.817 & 0.648 & 0.668 & 32.797 & .000 \\
\hline
\end{tabular}

The significance value of the regression shown in Table.10 indicates that at $p<0.05$ the regression model is fit. The $R$ value indicates a high degree of correlation. The $R^{2}$ value indicates that $66.8 \%$ of the total variation in the dependent variable can be explained by the independent variable.

Table.11. Coefficients of the MLR for male employees

\begin{tabular}{|c|c|c|c|}
\hline Factors & $\boldsymbol{\beta}$ & $\mathbf{t}$ & Sig. \\
\hline (Constant) & -0.267 & -0.745 & 0.458 \\
\hline $\mathrm{A} 1$ & 0.173 & 3.490 & .001 \\
\hline
\end{tabular}




\begin{tabular}{|c|c|c|c|}
\hline Factors & $\boldsymbol{\beta}$ & $\mathbf{t}$ & Sig. \\
\hline A2 & 0.171 & 3.479 & .001 \\
\hline A3 & 0.358 & 7.466 & .000 \\
\hline A4 & 0.271 & 5.744 & .000 \\
\hline A5 & 0.278 & 5.877 & .000 \\
\hline A6 & 0.308 & 6.585 & .000 \\
\hline A7 & 0.288 & 6.148 & .000 \\
\hline A8 & 0.307 & 6.541 & .000 \\
\hline A9 & 0.269 & 5.504 & .000 \\
\hline A10 & 0.256 & 5.226 & .000 \\
\hline
\end{tabular}

The regression equation formed from the coefficients presented in Table.11 is as follows:

$$
\begin{aligned}
\mathrm{Y} & =-0.267+0.173 \beta_{1}+0.171 \beta_{2}+0.358 \beta_{3}+0.271 \beta_{4}+0.278 \beta_{5} \\
& +0.308 \beta_{6}+0.288 \beta_{7}+0.307 \beta_{8}+0.269 \beta_{9}+0.256 \beta_{10}
\end{aligned}
$$

Table.12. Impact on individual factors of P-O fit of male employees using SLR

\begin{tabular}{|c|c|c|c|c|c|c|c|}
\hline \multirow{2}{*}{ Variables } & \multirow{2}{*}{$\mathbf{R}$} & \multirow{2}{*}{ Adj $\mathbf{R}^{2}$} & $\mathbf{t}$ & \multirow{2}{*}{ Reg coeff } & \multicolumn{3}{|c|}{ Change Statistics } \\
\hline & & & & & $\mathbf{R}^{\mathbf{2}}$ & $\mathbf{F}$ & Sig. \\
\hline A2 & 0.158 & 0.019 & 2.104 & 0.092 & 0.025 & 4.426 & .037 \\
\hline A3 & 0.378 & 0.138 & 5.349 & 0.157 & 0.143 & 28.615 & .000 \\
\hline A4 & 0.244 & 0.054 & 3.305 & 0.139 & 0.060 & 10.925 & .001 \\
\hline A5 & 0.245 & 0.055 & 3.314 & 0.127 & 0.060 & 10.980 & .001 \\
\hline A6 & 0.218 & 0.042 & 2.934 & 0.106 & 0.048 & 8.609 & .004 \\
\hline A7 & 0.307 & 0.089 & 4.228 & 0.176 & 0.094 & 17.876 & .000 \\
\hline A8 & 0.283 & 0.075 & 3.876 & 0.162 & 0.080 & 15.022 & .000 \\
\hline A9 & 0.251 & 0.058 & 3.407 & 0.141 & 0.063 & 11.607 & .001 \\
\hline A10 & 0.265 & 0.065 & 3.608 & 0.179 & 0.070 & 13.015 & .000 \\
\hline
\end{tabular}

The regression and the respective coefficients of the individual antecedents of P-O fit for the male employees are shown in Table.12. Unlike the female employees it can be seen that for male employees, all the factors except principles congruence have a very significant impact on their P-O fit at $p<0.05$.

\subsection{IMPACT OF FACTORS INFLUENCING $P$ - $O$ FIT - BY AGE GROUP}

This section examines the impact of the various antecedents of P-O fit on the employees distinguished based on their age. The Table.13, Table.14 and Table.15 present the outcomes of employees in the age group of 20 years to 30 years, Tables 16, 17 and 18 present the outcomes of employees in the age group of 31 years to 40 years while Table.19 present the outcomes of employees in the age group of 41 years to 50 years.

Table.13. Impact of all antecedents influencing P-O fit for employees in the age group of 20 years to 30 years

\begin{tabular}{|l|c|c|c|c|c|}
\hline \multirow{2}{*}{ Variables } & \multirow{2}{*}{$\mathbf{R}$} & \multirow{2}{*}{ Adj $^{2}$} & \multicolumn{3}{|c|}{ Change Statistics } \\
\cline { 4 - 6 } & & & $\mathbf{R}^{\mathbf{2}}$ & $\mathbf{F}$ & Sig. \\
\hline All Variables & 0.812 & 0.624 & 0.659 & 18.765 .000 \\
\hline
\end{tabular}

The model summary in Table.13 shows the overall fit statistics. The regression significance shows that " $p$ " is less than 0.05 which indicates that the regression model is fit. The $R$ value indicates a high degree of correlation. The $R^{2}$ value indicates that $65.9 \%$ of the total variation in the dependent variable can be explained by the independent variable. The $R^{2}$ is sufficiently large.

Table.14. Coefficients of the MLR for employees in the age group of 20 years to 30 years

\begin{tabular}{|c|c|c|c|}
\hline Factors & $\boldsymbol{\beta}$ & $\mathbf{t}$ & Sig. \\
\hline (Constant) & 0.211 & 0.486 & .628 \\
\hline A1 & 0.152 & 2.809 & .006 \\
\hline A2 & 0.115 & 3.172 & .002 \\
\hline A3 & 0.128 & 5.117 & .000 \\
\hline A4 & 0.182 & 5.105 & .000 \\
\hline A5 & 0.094 & 2.995 & .003 \\
\hline A6 & 0.141 & 4.964 & .000 \\
\hline A7 & 0.163 & 5.422 & .000 \\
\hline A8 & 0.121 & 3.869 & .000 \\
\hline A9 & 0.150 & 3.568 & .001 \\
\hline A10 & 0.145 & 3.723 & .000 \\
\hline
\end{tabular}

The regression equation formed from the coefficients presented in Table.14 is as follows:

$\mathrm{Y}=0.211+0.152 \beta_{1}+0.115 \beta_{2}+0.128 \beta_{3}+0.182 \beta_{4}+0.094 \beta_{5}+$ $0.141 \beta_{6}+0.163 \beta_{7}+0.121 \beta_{8}+0.150 \beta_{9}+0.145 \beta_{10}$

Table.15. Impact of individual factors influencing P-O fit of employees in the age group of 20 years to 30 years

\begin{tabular}{|c|c|c|c|c|c|c|c|}
\hline \multirow{2}{*}{ Variables } & \multirow{2}{*}{$\mathbf{R}$} & \multirow{2}{*}{ Adj $\mathbf{R}^{\mathbf{2}}$} & $\mathbf{t}$ & \multicolumn{2}{|c|}{ Reg coeff } & \multicolumn{2}{|c|}{ Change Statistics } \\
\hline & & & & & $\mathbf{F}$ & Sig. \\
\hline A2 & 0.270 & 0.064 & 2.890 & 0.144 & 0.073 & 8.349 & .005 \\
\hline A3 & 0.373 & 0.131 & 4.139 & 0.148 & 0.139 & 17.132 & .000 \\
\hline A4 & 0.307 & 0.085 & 3.316 & 0.175 & 0.094 & 10.995 & .001 \\
\hline A7 & 0.306 & 0.085 & 3.312 & 0.148 & 0.094 & 10.968 & .001 \\
\hline A8 & 0.337 & 0.105 & 3.687 & 0.170 & 0.114 & 13.597 & .000 \\
\hline A9 & 0.328 & 0.099 & 3.572 & 0.198 & 0.107 & 12.756 & .001 \\
\hline A10 & 0.204 & 0.033 & 2.145 & 0.125 & 0.042 & 4.601 & .034 \\
\hline
\end{tabular}

The Table.15 shows the effect of the various independent variables on the P-O fit of employees in the age group of 20 years to 30 years. The regression coefficients of the variables of P-O fit for these employees are also shown in table. Unlike the employees with lesser experience, here the variables principles congruence, ability congruence and personal skills congruence don't have a significant impact on the $\mathrm{P}-\mathrm{O}$ fit at $p<0.05$.

Table.16. Impact of all antecedents influencing P-O fit for employees in the age group of 31 years to 40 years

\begin{tabular}{|l|c|c|c|c|c|}
\hline \multirow{2}{*}{ Variables } & \multirow{2}{*}{$\mathbf{R}$} & \multirow{2}{*}{ Adj R $^{2}$} & \multicolumn{3}{|c|}{ Change Statistics } \\
\cline { 4 - 6 } & & & $\mathbf{R}^{\mathbf{2}}$ & $\mathbf{F}$ & Sig. \\
\hline All Variables & 0.825 & 0.653 & 0.680 & 25.068 & .000 \\
\hline
\end{tabular}


The regression model summary shown in in Table.16 indicates that the model's fit is statistically significant $(p<0.05)$. The $\mathrm{R}$ value indicates a high degree of correlation. The $R^{2}$ value indicates that $68.0 \%$ of the total variation in the dependent variable can be explained by the independent variable. The $R^{2}$ is sufficiently large.

Table17. Coefficients of the MLR for employees in the age group of 31 years to 40 years

\begin{tabular}{|c|c|c|c|}
\hline Factors & $\boldsymbol{\beta}$ & $\mathbf{t}$ & Sig. \\
\hline (Constant) & -0.527 & -1.263 & .209 \\
\hline A1 & 0.172 & 3.416 & .001 \\
\hline A2 & 0.133 & 3.977 & .000 \\
\hline A3 & 0.167 & 7.100 & .000 \\
\hline A4 & 0.157 & 5.208 & .000 \\
\hline A5 & 0.146 & 5.496 & .000 \\
\hline A6 & 0.142 & 5.208 & .000 \\
\hline A7 & 0.141 & 4.648 & .000 \\
\hline A8 & 0.174 & 5.326 & .000 \\
\hline A9 & 0.148 & 5.024 & .000 \\
\hline A10 & 0.207 & 5.334 & .000 \\
\hline
\end{tabular}

The regression equation formed from the coefficients presented in Table. 17 is as follows:

$\mathrm{Y}=-0.527+0.172 \beta_{1}+0.133 \beta_{2}+0.167 \beta_{3}+0.157 \beta_{4}+0.146 \beta_{5}+$ $0.142 \beta_{6}+0.141 \beta_{7}+0.174 \beta_{8}+0.148 \beta_{9}+0.207 \beta_{10}$

Table.18. Impact of individual factors influencing P-O fit of employees in the age group of 31 years to 40 years

\begin{tabular}{|c|c|c|c|c|c|c|c|}
\hline \multirow{2}{*}{ Variables } & \multirow{2}{*}{$\mathbf{R}$} & \multirow{2}{*}{$\begin{array}{c}\text { Adj } \\
\mathbf{R}^{\mathbf{2}}\end{array}$} & $\mathbf{t}$ & \multirow{2}{*}{$\begin{array}{c}\text { Reg } \\
\text { coeff }\end{array}$} & \multicolumn{2}{|c|}{ Change Statistics } \\
\cline { 6 - 8 } & & & $\mathbf{R}^{\mathbf{2}}$ & $\mathbf{F}$ & Sig. \\
\hline A3 & 0.390 & 0.145 & 4.768 & 0.164 & 0.152 & 22.738 & .000 \\
\hline A4 & 0.191 & 0.029 & 2.193 & 0.105 & 0.036 & 4.810 & .030 \\
\hline A5 & 0.214 & 0.038 & 2.471 & 0.103 & 0.046 & 6.103 & .015 \\
\hline A6 & 0.238 & 0.049 & 2.765 & 0.117 & 0.057 & 7.647 & .007 \\
\hline A7 & 0.275 & 0.068 & 3.209 & 0.151 & 0.075 & 10.300 & .002 \\
\hline A8 & 0.224 & 0.043 & 2.592 & 0.131 & 0.050 & 6.718 & .011 \\
\hline A9 & 0.254 & 0.057 & 2.962 & 0.134 & 0.065 & 8.775 & .004 \\
\hline A10 & 0.339 & 0.108 & 4.065 & 0.235 & 0.115 & 16.525 & .000 \\
\hline
\end{tabular}

While observing Table.18 it can be seen that except the factors Principles congruence and values and norms congruence all other factors have a significant impact on the P-O fit at $p<0.05$ for employees in the age group of 31 years to 40 years.

Table.19. Impact on factors influencing P-O fit of employees in the age group of 41 years to 50 years

\begin{tabular}{|c|c|c|c|c|c|c|c|}
\hline \multirow{2}{*}{ Variables } & \multirow{2}{*}{$\mathbf{R}$} & \multirow{2}{*}{$\begin{array}{c}\text { Adj } \\
\mathbf{R}^{\mathbf{2}}\end{array}$} & \multirow{2}{*}{$\mathbf{t}$} & \multirow{2}{*}{$\begin{array}{c}\text { Reg } \\
\text { coeff }\end{array}$} & \multicolumn{3}{|c|}{ Change Statistics } \\
\cline { 6 - 9 } & & & $\mathbf{R}^{\mathbf{2}}$ & $\mathbf{F}$ & Sig. \\
\hline A3 & 0.878 & 0.714 & 3.674 & 0.857 & 0.771 & 13.500 & .021 \\
\hline A7 & 0.894 & 0.750 & 4.000 & 1.333 & 0.800 & 16.000 & .016 \\
\hline
\end{tabular}

Since there are only six members in the age group of 41 years to 50 years, MLR is not possible and only the results of the variables having significant impact on $\mathrm{P}-\mathrm{O}$ fit is compiled.

\subsection{IMPACT OF FACTORS INFLUENCING P-O FIT - BY DESIGNATION}

The following section examines the impact of the various antecedents of P-O fit on the employees distinguished based on their managerial or non-managerial position in the organisation. The Table.20, Table.21 and Table.22 present the outcomes of managerial employees and Table.23, Table.24 and Table.25 present the outcomes of non-managerial employees.

Table.20. Impact of all antecedents influencing P-O fit for Managerial employees using MLR

\begin{tabular}{|c|c|c|c|c|c|}
\hline \multirow{2}{*}{ Variables } & \multirow{2}{*}{$\mathbf{R}$} & \multirow{2}{*}{ Adj $\mathbf{R}^{\mathbf{2}}$} & \multicolumn{3}{|c|}{ Change Statistics } \\
\cline { 4 - 6 } & & & $\mathbf{R}^{\mathbf{2}}$ & $\mathbf{F}$ & Sig. \\
\hline All Variables & 0.893 & 0.653 & 0.798 & 5.525 & .000 \\
\hline
\end{tabular}

While considering all the variables in the regression for managerial employees, it can be seen that the regression significance ' $p$ ' is less than 0.05 which indicates that the regression model is fit. The $R$ value indicates a high degree of correlation. The $R^{2}$ value indicates that $79.8 \%$ of the total variation in the dependent variable can be explained by the independent variable and is sufficiently large.

Table.21. Coefficients of the MLR for managerial employees

\begin{tabular}{|c|c|c|c|}
\hline Factors & $\boldsymbol{\beta}$ & $\mathbf{t}$ & Sig. \\
\hline (Constant) & -.766 & -.705 & .492 \\
\hline A5 & 0.170 & 2.370 & .033 \\
\hline A6 & 0.183 & 2.908 & .011 \\
\hline A8 & 0.181 & 2.587 & .022 \\
\hline A9 & 0.333 & 3.942 & .001 \\
\hline
\end{tabular}

The regression equation formed for the managerial employees from the coefficients presented in Table. 21 is as follows:

$$
Y=-0.766+0.170 \beta_{5}+0.183 \beta_{6}+0.181 \beta_{8}+0.333 \beta_{9}
$$

Table.22. Impact of individual factors influencing P-O fit using SLR for managerial employees

\begin{tabular}{|c|c|c|c|c|c|c|c|}
\hline \multirow{2}{*}{ Variables } & \multirow{2}{*}{$\mathbf{R}$} & \multirow{2}{*}{$\begin{array}{c}\text { Adj } \\
\mathbf{R}^{\mathbf{2}}\end{array}$} & $\mathbf{T}$ & \multirow{2}{*}{$\begin{array}{c}\text { Reg } \\
\text { coeff }\end{array}$} & \multicolumn{3}{|c|}{ Change Statistics } \\
\cline { 5 - 8 } & & & $\mathbf{R}^{\mathbf{2}}$ & $\mathbf{F}$ & Sig. \\
\hline A4 & 0.468 & 0.185 & 2.540 & 0.279 & 0.219 & 6.451 & .018 \\
\hline A8 & 0.464 & 0.181 & 2.509 & 0.233 & 0.215 & 6.294 & .020 \\
\hline
\end{tabular}

The outcomes of the regression of $\mathrm{P}-\mathrm{O}$ fit for the managerial employees are shown in Table.22. Here, almost all of the factors except need congruence and personality congruence don't have a significant impact on their P-O fit at $p<0.05$. However even these two factors exhibit a poor impact on $\mathrm{P}-\mathrm{O}$ fit. The regression equation can be presented in the form of $Y=a+\beta x$, where $Y$ is the overall feeling of male employee's fit in the organisation and $\beta$ is the regression coefficient of the respective antecedent and $x$ is the antecedent of $\mathrm{P}-\mathrm{O}$ fit. 
Table.23. Impact of all antecedents influencing P-O fit for nonmanagerial employees using MLR

\begin{tabular}{|c|c|c|c|c|c|}
\hline \multirow{2}{*}{ Variables } & \multirow{2}{*}{$\mathbf{R}$} & \multirow{2}{*}{ Adj $\mathbf{R}^{\mathbf{2}}$} & \multicolumn{3}{|c|}{ Change Statistics } \\
\cline { 3 - 6 } & & & $\mathbf{R}^{\mathbf{2}}$ & $\mathbf{F}$ & Sig. \\
\hline All Variables & 0.821 & 0.658 & 0.674 & 42.837 & .000 \\
\hline
\end{tabular}

A MLR was done to identify the impact of the antecedents of $\mathrm{P}-\mathrm{O}$ fit and the results (Table.23) shows that the regression model is fit at $p<0.05$. The $R$ value indicates a high degree of correlation. The $R^{2}$ value indicates that $67.4 \%$ of the total variation in the dependent variable can be explained by the independent variable.

Table.24. Coefficients of the MLR for non-managerial employees

\begin{tabular}{|c|c|c|c|}
\hline Factors & $\boldsymbol{\beta}$ & $\mathbf{t}$ & Sig. \\
\hline (Constant) & -0.251 & -.817 & .415 \\
\hline A1 & 0.164 & 4.358 & .000 \\
\hline A2 & 0.136 & 5.431 & .000 \\
\hline A3 & 0.152 & 8.821 & .000 \\
\hline A4 & 0.161 & 6.914 & .000 \\
\hline A5 & 0.130 & 6.326 & .000 \\
\hline A6 & 0.135 & 6.671 & .000 \\
\hline A7 & 0.154 & 7.119 & .000 \\
\hline A8 & 0.148 & 6.448 & .000 \\
\hline A9 & 0.137 & 5.564 & .000 \\
\hline A10 & 0.197 & 6.865 & .000 \\
\hline
\end{tabular}

The regression equation formed from the coefficients presented in Table. 24 is as follows:

$Y=-0.251+0.164 \beta_{1}+0.136 \beta_{2}+0.152 \beta_{3}+0.161 \beta_{4}+0.130 \beta_{5}+$ $0.135 \beta_{6}+0.154 \beta_{7}+0.148 \beta_{8}+0.137 \beta_{9}+0.197 \beta_{10}$

Table.25. Impact of individual antecedents on factors influencing P-O fit of non-managerial employees

\begin{tabular}{|c|c|c|c|c|c|c|c|}
\hline \multirow{2}{*}{ Variables } & \multirow{2}{*}{$\mathbf{R}$} & \multirow{2}{*}{$\begin{array}{c}\text { Adj } \\
\mathbf{R}^{\mathbf{2}}\end{array}$} & \multirow{2}{*}{$\mathbf{t}$} & \multirow{2}{*}{$\begin{array}{l}\text { Reg } \\
\text { coeff }\end{array}$} & \multicolumn{3}{|c|}{ Change Statistics } \\
\cline { 6 - 9 } & & & $\mathbf{R}^{\mathbf{2}}$ & $\mathbf{F}$ & Sig. \\
\hline A2 & 0.221 & 0.045 & 3.338 & 0.129 & 0.049 & 11.141 & .001 \\
\hline A3 & 0.401 & 0.157 & 6.443 & 0.165 & 0.161 & 41.506 & .000 \\
\hline A4 & 0.233 & 0.050 & 3.526 & 0.132 & 0.054 & 12.434 & .001 \\
\hline A5 & 0.199 & 0.035 & 2.989 & 0.100 & 0.040 & 8.932 & .003 \\
\hline A6 & 0.222 & 0.045 & 3.350 & 0.109 & 0.049 & 11.220 & .001 \\
\hline A7 & 0.300 & 0.086 & 4.628 & 0.158 & 0.090 & 21.421 & .000 \\
\hline A8 & 0.256 & 0.066 & 4.046 & 0.149 & 0.070 & 16.369 & .000 \\
\hline A9 & 0.274 & 0.071 & 4.184 & 0.156 & 0.075 & 17.507 & .000 \\
\hline A10 & 0.275 & 0.072 & 4.211 & 0.189 & 0.076 & 17.730 & .000 \\
\hline
\end{tabular}

The regression coefficients of the individual antecedents of $\mathrm{P}$ $\mathrm{O}$ fit for the non-managerial employees are shown in Table.25. Unlike the managerial employees, it can be seen that for nonmanagerial employees, all the factors except principle congruence have a very significant impact on their P-O fit at $p<0.05$.

\subsection{IMPACT OF FACTORS INFLUENCING $P$ - $O$ FIT - BY EDUCATIONAL QUALIFICATION}

The following section examines the impact of the various antecedents of P-O fit on the employees distinguished based on their educational qualification. The Table.26, Table.27 and Table.28 present the outcomes of employees with ITI qualification, Table.29, Table.30 and Table.31 present the outcomes of employees with polytechnic qualification, Table.32, Table. 33 and Table. 34 presents the outcomes of employees with UG qualification and Table.35, Table.36 and Table. 37 presents the outcomes of employees with PG qualification.

Table.26. Impact of all antecedents influencing P-O fit for employees with ITI qualification using multiple regression

\begin{tabular}{|c|c|c|c|c|c|}
\hline \multirow{2}{*}{ Variables } & \multirow{2}{*}{$\mathbf{R}$} & \multirow{2}{*}{$\operatorname{Adj~}_{\mathbf{2}}$} & \multicolumn{3}{|c|}{ Change Statistics } \\
\cline { 4 - 6 } & & & $\mathbf{R}^{\mathbf{2}}$ & $\mathbf{F}$ & Sig. \\
\hline All Variables & 0.862 & 0.710 & 0.743 & 22.027 & .000 \\
\hline
\end{tabular}

The regression model summary with its significance $(p<0.05)$ is shown in Table.26. The significance value indicates that the regression model is fit. The $R$ value indicates a high degree of correlation. The $R^{2}$ value is sufficiently large and indicates that $74.3 \%$ of the total variation in the dependent variable can be explained by the independent variable.

Table.27. Coefficients of the MLR for employees with ITI qualification

\begin{tabular}{|c|c|c|c|}
\hline Factors & $\boldsymbol{\beta}$ & $\mathbf{t}$ & Sig. \\
\hline (Constant) & -0.377 & -.857 & .394 \\
\hline A1 & 0.192 & 3.458 & .001 \\
\hline A3 & 0.182 & 6.897 & .000 \\
\hline A4 & 0.194 & 5.149 & .000 \\
\hline A5 & 0.153 & 5.186 & .000 \\
\hline A6 & 0.151 & 4.738 & .000 \\
\hline A7 & 0.182 & 5.486 & .000 \\
\hline A8 & 0.133 & 3.838 & .000 \\
\hline A9 & 0.185 & 4.898 & .000 \\
\hline A10 & 0.115 & 2.665 & .009 \\
\hline
\end{tabular}

From the Table.27 it can be seen that the factor values and norms congruence does not have a significant impact on $\mathrm{P}-\mathrm{O}$ fit for employees with ITI qualification. Thus the regression equation formed from the coefficients presented in Table. 27 is as follows:

$$
Y=-0.377+0.192 \beta_{1}+0.182 \beta_{3}+0.194 \beta_{4}+0.153 \beta_{5}+0.151 \beta_{6}
$$
$+0.182 \beta_{7}+0.133 \beta_{8}+0.185 \beta_{9}+0.115 \beta_{10}$

Table.28. Impact of individual factors influencing P-O fit of employees with ITI qualification

\begin{tabular}{|c|c|c|c|c|c|c|c|}
\hline \multirow{2}{*}{ Variables } & \multirow{2}{*}{$\mathbf{R}$} & \multirow{2}{*}{$\begin{array}{c}\text { Adj } \\
\mathbf{R}^{\mathbf{2}}\end{array}$} & \multirow{2}{*}{$\mathbf{t}$} & \multirow{2}{*}{$\begin{array}{c}\text { Reg } \\
\text { coeff }\end{array}$} & \multicolumn{3}{|c|}{ Change Statistics } \\
\cline { 6 - 8 } & & & $\mathbf{R}^{\mathbf{2}}$ & $\mathbf{F}$ & Sig. \\
\hline A3 & 0.462 & 0.213 & 4.797 & 0.192 & 0.213 & 23.013 & .000 \\
\hline A4 & 0.298 & 0.078 & 2.881 & 0.188 & 0.089 & 8.303 & .005 \\
\hline
\end{tabular}




\begin{tabular}{|c|c|c|c|c|c|c|c|}
\hline \multirow{2}{*}{ Variables } & \multirow{2}{*}{$\mathbf{R}$} & \multirow{2}{*}{$\begin{array}{c}\text { Adj } \\
\mathbf{R}^{\mathbf{2}}\end{array}$} & \multirow{2}{*}{$\mathbf{t}$} & \multirow{2}{*}{$\begin{array}{c}\text { Reg } \\
\text { coeff }\end{array}$} & \multicolumn{2}{|c|}{ Change Statistics } \\
\cline { 6 - 8 } & & & $\mathbf{R}^{\mathbf{2}}$ & $\mathbf{F}$ & Sig. \\
\hline A6 & 0.237 & 0.045 & 2.253 & 0.121 & 0.056 & 5.075 & .027 \\
\hline A7 & 0.309 & 0.085 & 3.001 & 0.160 & 0.096 & 9.003 & .004 \\
\hline A8 & 0.249 & 0.051 & 2.371 & 0.141 & 0.062 & 5.624 & .020 \\
\hline A9 & 0.268 & 0.061 & 2.568 & 0.149 & 0.072 & 6.596 & .012 \\
\hline
\end{tabular}

The results of the regressions and the respective coefficients of the individual antecedents of P-O fit for the employees with ITI qualification are shown in Table.28. In this case, factors such as principles congruence, values and norms congruence, ability and work place congruence don't have a significant impact on their $\mathrm{P}$ $\mathrm{O}$ fit at $p<0.05$.

Table.29. Impact of all antecedents influencing P-O fit for employees with polytechnic qualification

\begin{tabular}{|l|c|c|c|c|c|}
\hline \multirow{2}{*}{ Variables } & \multirow{2}{*}{$\mathbf{R}$} & \multirow{2}{*}{ Adj $^{2}$} & \multicolumn{3}{|c|}{ Change Statistics } \\
\cline { 4 - 6 } & & & $\mathbf{R}^{\mathbf{2}}$ & $\mathbf{F}$ & Sig. \\
\hline All Variables & 0.802 & 0.595 & 0.644 & 13.190 .000 \\
\hline
\end{tabular}

The significance value of the model summary of the regression for employees with polytechnic qualification is shown in Table.29. The significance value is less than 0.05 which indicates that the regression model is fit. The $R$ value indicates a high degree of correlation. The $R^{2}$ value indicates that $64.4 \%$ of the total variation in the dependent variable can be explained by the independent variable.

Table.30. Coefficients of the MLR for employees with polytechnic qualification

\begin{tabular}{|c|c|c|c|}
\hline Factors & $\boldsymbol{\beta}$ & $\mathbf{t}$ & Sig. \\
\hline (Constant) & 0.052 & 0.091 & .928 \\
\hline A2 & 0.169 & 3.588 & .001 \\
\hline A3 & 0.129 & 4.579 & .000 \\
\hline A4 & 0.120 & 2.997 & .004 \\
\hline A5 & 0.084 & 2.446 & .017 \\
\hline A6 & 0.129 & 3.821 & .000 \\
\hline A7 & 0.156 & 3.950 & .000 \\
\hline A8 & 0.117 & 3.028 & .003 \\
\hline A9 & 0.128 & 3.080 & .003 \\
\hline A10 & 0.276 & 5.813 & .000 \\
\hline
\end{tabular}

The regression equation formed from the coefficients presented in Table. 30 is as follows:

$Y=0.052+0.169 \beta_{2}+0.129 \beta_{3}+0.120 \beta_{4}+0.084 \beta_{5}+0.129 \beta_{6}+$ $0.156 \beta_{7}+0.117 \beta_{8}+0.128 \beta_{9}+0.276 \beta_{10}$

Table.31. Impact of individual factors influencing P-O fit of employees with polytechnic qualification

\begin{tabular}{|c|c|c|c|c|c|c|c|}
\hline \multirow{2}{*}{ Variables } & \multirow{2}{*}{$\mathbf{R}$} & \multirow{2}{*}{$\begin{array}{c}\text { Adj } \\
\mathbf{R}^{\mathbf{2}}\end{array}$} & $\mathbf{t}$ & \multirow{2}{*}{$\begin{array}{c}\text { Reg } \\
\text { coeff }\end{array}$} & \multicolumn{3}{|c|}{ Change Statistics } \\
\cline { 5 - 8 } & & $\mathbf{R}^{\mathbf{2}}$ & $\mathbf{F}$ & Sig. \\
\hline A2 & 0.256 & 0.054 & 2.394 & 0.146 & 0.065 & 5.731 & .019 \\
\hline A3 & 0.319 & 0.091 & 3.045 & 0.117 & 0.102 & 9.272 & .003 \\
\hline
\end{tabular}

\begin{tabular}{|c|c|c|c|c|c|c|c|}
\hline A6 & 0.258 & 0.055 & 2.419 & 0.115 & 0.067 & 5.854 & .018 \\
\hline A7 & 0.303 & 0.081 & 2.884 & 0.164 & 0.092 & 8.317 & .005 \\
\hline A9 & 0.291 & 0.074 & 2.756 & 0.160 & 0.085 & 7.598 & .007 \\
\hline A10 & 0.341 & 0.106 & 3.287 & 0.220 & 0.116 & 10.802 & .001 \\
\hline
\end{tabular}

The Table.31. shows the regression and the respective coefficients of the individual antecedents of P-O fit for the employees with polytechnic qualification. The factors with $p>0.05$ don't have a significant impact on $\mathrm{P}-\mathrm{O}$ fit.

Table.32. Impact of all antecedents influencing P-O fit for employees with UG qualification

\begin{tabular}{|l|c|c|c|c|c|}
\hline \multirow{2}{*}{ Variables } & \multirow{2}{*}{$\mathbf{R}$} & \multirow{2}{*}{ Adj $^{2}$} & \multicolumn{3}{|c|}{ Change Statistics } \\
\cline { 4 - 6 } & & & $\mathbf{R}^{\mathbf{2}}$ & $\mathbf{F}$ & Sig. \\
\hline All Variables & 0.812 & 0.584 & 0.660 & 8.728 & .000 \\
\hline
\end{tabular}

The significance value of the regression for employees with UG qualification is shown in Table.32. The significance value shows that ' $p$ ' is less than 0.05 which indicates that the regression model is fit. The $R$ value indicates a high degree of correlation. The $R^{2}$ value indicates that $66.0 \%$ of the total variation in the dependent variable can be explained by the independent variable.

Table.33. Coefficients of the MLR for employees with UG qualification

\begin{tabular}{|c|c|c|c|}
\hline Factors & $\boldsymbol{\beta}$ & $\mathbf{t}$ & Sig. \\
\hline (Constant) & -0.364 & -0.474 & .638 \\
\hline A2 & 0.152 & 2.213 & .032 \\
\hline A3 & 0.164 & 3.929 & .000 \\
\hline A4 & 0.161 & 3.254 & .002 \\
\hline A5 & 0.179 & 3.052 & .004 \\
\hline A6 & 0.105 & 2.206 & .033 \\
\hline A7 & 0.153 & 3.058 & .004 \\
\hline A8 & 0.164 & 2.760 & .008 \\
\hline A10 & 0.195 & 2.717 & .009 \\
\hline
\end{tabular}

The regression equation formed from the coefficients presented in Table.33 is as follows:

$Y=-0.364+0.152 \beta_{2}+0.164 \beta_{3}+0.161 \beta_{4}+0.179 \beta_{5}+0.105 \beta_{6}$ $+0.153 \beta_{7}+0.164 \beta_{8}+0.195 \beta_{10}$

Table.34. Impact of individual factors influencing P-O fit of employees with UG qualification

\begin{tabular}{|c|c|c|c|c|c|c|c|}
\hline \multirow{2}{*}{ Variables } & \multirow{2}{*}{$\mathbf{R}$} & \multirow{2}{*}{$\begin{array}{c}\text { Adj } \\
\mathbf{R}^{\mathbf{2}}\end{array}$} & \multirow{2}{*}{$\mathbf{t}$} & \multirow{2}{*}{$\begin{array}{c}\text { Reg } \\
\text { coeff }\end{array}$} & \multicolumn{2}{|c|}{ Change Statistics } \\
\cline { 6 - 9 } & & & $\mathbf{R}^{\mathbf{2}}$ & $\mathbf{F}$ & Sig. \\
\hline A3 & 0.418 & 0.159 & 3.376 & 0.195 & 0.174 & 11.401 & .001 \\
\hline A7 & 0.280 & 0.061 & 2.141 & 0.149 & 0.078 & 4.583 & .037 \\
\hline A8 & 0.381 & 0.129 & 3.026 & 0.225 & 0.145 & 9.156 & .004 \\
\hline A9 & 0.336 & 0.097 & 2.624 & 0.193 & 0.113 & 6.885 & .011 \\
\hline A10 & 0.285 & 0.064 & 2.186 & 0.202 & 0.081 & 4.778 & .033 \\
\hline
\end{tabular}

The outcomes of the regression for the employees with UG qualification are shown in Table.34. Here too there are factors that don't have significant impact on their P-O fit at $p<0.05$. 
Table.35. Impact of all antecedents influencing P-O fit for employees with PG qualification

\begin{tabular}{|c|c|c|c|c|c|}
\hline \multirow{2}{*}{ Variables } & \multirow{2}{*}{$\mathbf{R}$} & \multirow{2}{*}{ Adj $\mathbf{R}^{\mathbf{2}}$} & \multicolumn{3}{|c|}{ Change Statistics } \\
\cline { 4 - 6 } & & & $\mathbf{R}^{\mathbf{2}}$ & $\mathbf{F}$ & Sig. \\
\hline All Variables & 0.975 & 0.854 & 0.951 & 9.747 & .000 \\
\hline
\end{tabular}

The regression results and the significance at $\mathrm{p}<0.05$ of the multiple regression is revealed in Table.35. The significance value shows that the regression model is fit. The $R$ value indicates a very high degree of correlation. The $R^{2}$ value indicates that $95.1 \%$ of the total variation in the dependent variable can be explained by the independent variable. The $R^{2}$ is sufficiently large.

Table.36. Coefficients of the MLR for employees with PG qualification

\begin{tabular}{|c|c|c|c|}
\hline Factors & $\boldsymbol{\beta}$ & $\mathbf{t}$ & Sig. \\
\hline (Constant) & -0.564 & -0.320 & .762 \\
\hline A4 & 0.323 & 2.731 & .041 \\
\hline A6 & 0.209 & 3.414 & .019 \\
\hline A9 & 0.276 & 2.617 & .047 \\
\hline
\end{tabular}

The regression equation formed from the coefficients presented in Table.36 is as follows:

$$
Y=-0.564+0.323 \beta_{4}+0.209 \beta_{6}+0.276 \beta_{9}
$$

Table.37. Impact of factors influencing P-O fit of employees with $\mathrm{PG}$ qualification

\begin{tabular}{|c|c|c|c|c|c|c|c|}
\hline \multirow{2}{*}{ Variables } & \multirow{2}{*}{$\mathbf{R}$} & \multirow{2}{*}{$\begin{array}{c}\text { Adj } \\
\mathbf{R}^{\mathbf{2}}\end{array}$} & \multirow{2}{*}{$\mathbf{t}$} & \multirow{2}{*}{$\begin{array}{c}\text { Reg } \\
\text { coeff }\end{array}$} & \multicolumn{2}{|c|}{ Change Statistics } \\
\cline { 6 - 8 } & & & $\mathbf{R}^{\mathbf{2}}$ & $\mathbf{F}$ & Sig. \\
\hline A4 & 0.612 & 0.330 & 2.894 & 0.335 & 0.375 & 8.374 & .012 \\
\hline A5 & 0.586 & 0.297 & 2.709 & 0.292 & 0.344 & 7.337 & .017 \\
\hline A6 & 0.529 & 0.228 & 2.333 & 0.258 & 0.280 & 5.441 & .035 \\
\hline
\end{tabular}

The Table. 37 presents the regression significance at $p<0.05$ and the respective coefficients of the individual antecedents of $\mathrm{P}$ $\mathrm{O}$ fit for the employees with PG qualification. For this category of employees, it can be seen that only three factors have a significant impact.

\subsection{IMPACT OF FACTORS INFLUENCING P-O FIT - BY EMPLOYEE EXPERIENCE}

The following section examines the impact of the various antecedents of P-O fit on the employees distinguished based on their educational qualification. The Table.38, Table.39 and Table. 40 present the outcomes of employees with 1 to 10 years of work experience at the present organisation and Table.41, Table.42 and Table.43 present the outcomes of employees with 11 to 20 years of work experience at the present organisation. Only two employees are there with more than 21 years of experience. Thus no meaningful analyses may be done on them.

Table.38. Impact of all antecedents influencing P-O fit for employees with 1 to 10 years of work experience at the present organisation

\begin{tabular}{|c|c|c|c|c|c|}
\hline \multirow{2}{*}{ Variables } & \multirow{2}{*}{$\mathbf{R}$} & \multirow{2}{*}{ Adj $\mathbf{R}^{\mathbf{2}}$} & \multicolumn{3}{|c|}{ Change Statistics } \\
\cline { 4 - 6 } & & & $\mathbf{R}^{\mathbf{2}}$ & $\mathbf{F}$ & Sig. \\
\hline All Variables & 0.824 & 0.656 & 0.678 & 30.581 & .000 \\
\hline
\end{tabular}

The Table.38. shows the multiple regression results of $\mathrm{P}-\mathrm{O}$ fit for employees with 1 to 10 years of work experience at the present organisation. Observing the tabulated values it can be seen that the regression model is fit at ' $p$ ' less than 0.005 and the correlation value $R$ is good. The $R^{2}$ value indicates that only $67.8 \%$ of the total variation in the dependent variable can be explained by the independent variable.

Table.39. Coefficients of the MLR for employees with 1 to 10 years of work experience at the present organisation

\begin{tabular}{|c|c|c|c|}
\hline Factors & $\boldsymbol{\beta}$ & $\mathbf{t}$ & Sig. \\
\hline (Constant) & -0.101 & -.293 & .770 \\
\hline A1 & 0.172 & 4.020 & .000 \\
\hline A2 & 0.129 & 4.482 & .000 \\
\hline A3 & 0.149 & 7.337 & .000 \\
\hline A4 & 0.165 & 5.831 & .000 \\
\hline A5 & 0.106 & 4.468 & .000 \\
\hline A6 & 0.147 & 6.600 & .000 \\
\hline A7 & 0.134 & 5.579 & .000 \\
\hline A8 & 0.149 & 5.581 & .000 \\
\hline A9 & 0.152 & 5.009 & .000 \\
\hline A10 & 0.170 & 5.518 & .000 \\
\hline
\end{tabular}

The regression equation formed from the coefficients presented in Table.39 is as follows:

$Y=-0.101+0.172 \beta_{1}+0.129 \beta_{2}+0.149 \beta_{3}+0.165 \beta_{4}+0.106 \beta_{5}$ $+0.147 \beta_{6}+0.134 \beta_{7}+0.149 \beta_{8}+0.152 \beta_{9}+0.170 \beta_{10}$

Table.40. Impact of factors influencing P-O fit of employees with 1 to 10 years of work experience at the present organisation

\begin{tabular}{|c|c|c|c|c|c|c|c|}
\hline \multirow{2}{*}{ Variables } & \multirow{2}{*}{$\mathbf{R}$} & \multirow{2}{*}{ Adj R } & \multirow{2}{*}{$\mathbf{t}$} & \multirow{2}{*}{ Reg coeff } & \multicolumn{3}{|c|}{ Change Statistics } \\
\hline & & & & & $\mathbf{R}^{\mathbf{2}}$ & $\mathbf{F}$ & Sig. \\
\hline A2 & 0.196 & 0.032 & 2.476 & 0.109 & 0.038 & 6.130 & .014 \\
\hline A3 & 0.383 & 0.141 & 5.138 & 0.153 & 0.146 & 26.394 & .000 \\
\hline A4 & 0.270 & 0.067 & 3.480 & 0.154 & 0.073 & 12.108 & .001 \\
\hline A6 & 0.259 & 0.061 & 3.330 & 0.118 & 0.067 & 11.092 & .001 \\
\hline A7 & 0.254 & 0.058 & 3.255 & 0.125 & 0.064 & 10.593 & .001 \\
\hline A8 & 0.283 & 0.074 & 3.667 & 0.157 & 0.080 & 13.445 & .000 \\
\hline A9 & 0.286 & 0.076 & 3.706 & 0.163 & 0.082 & 13.732 & .000 \\
\hline A10 & 0.278 & 0.077 & 3.592 & 0.173 & 0.077 & 12.905 & .000 \\
\hline
\end{tabular}

Table.40 expresses the regression results of antecedents of $\mathrm{P}$ $\mathrm{O}$ fit and the significance at $p<0.05$ for the employees with 1 to 10 years of work experience at the present organisation. For this category of employees, it can be seen that all the factors except principles congruence and ability congruence have a significant impact. 
Table.41. Impact of all antecedents influencing P-O fit for employees with 11 to 20 years of work experience at the present organisation

\begin{tabular}{|c|c|c|c|c|c|}
\hline \multirow{2}{*}{ Variables } & \multirow{2}{*}{$\mathbf{R}$} & \multirow{2}{*}{ Adj $\mathbf{R}^{\mathbf{2}}$} & \multicolumn{3}{|c|}{ Change Statistics } \\
\cline { 4 - 6 } & & & $\mathbf{R}^{\mathbf{2}}$ & $\mathbf{F}$ & Sig. \\
\hline All Variables & 0.815 & 0.619 & 0.664 & 14.651 & .000 \\
\hline
\end{tabular}

The MLR results of P-O fit for employees with 11 to 20 years of work experience at the present organisation is presented in Table.41. Noting the tabulated values it can be seen that the regression model is fit at ' $p$ ' less than 0.005 and the correlation value $R(0.815)$ is good. The $R^{2}$ value indicates that only $66.4 \%$ of the total variation in the dependent variable can be explained by the independent variable.

Table.42. Coefficients of the MLR for employees with 11 to 20 years of work experience at the present organisation

\begin{tabular}{|c|c|c|c|}
\hline Factors & $\boldsymbol{\beta}$ & $\mathbf{t}$ & Sig. \\
\hline (Constant) & -.357 & -.630 & .530 \\
\hline A1 & 0.155 & 2.199 & .031 \\
\hline A2 & 0.127 & 2.846 & .006 \\
\hline A3 & 0.151 & 4.818 & .000 \\
\hline A4 & 0.146 & 3.657 & .000 \\
\hline A5 & 0.164 & 4.368 & .000 \\
\hline A6 & 0.139 & 3.771 & .000 \\
\hline A7 & 0.185 & 4.331 & .000 \\
\hline A8 & 0.140 & 3.519 & .001 \\
\hline A9 & 0.134 & 3.261 & .002 \\
\hline A10 & 0.202 & 3.666 & .000 \\
\hline
\end{tabular}

The regression equation formed from the coefficients presented in Table. 42 is as follows:

$$
\begin{gathered}
Y=-0.357+0.155 \beta_{1}+0.127 \beta_{2}+0.151 \beta_{3}+0.146 \beta_{4}+0.164 \beta_{5}+ \\
0.139 \beta_{6}+0.185 \beta_{7}+0.140 \beta_{8}+0.134 \beta_{9}+0.202 \beta_{10}
\end{gathered}
$$

Table.43. Impact of factors influencing P-O fit of employees with 11 to 20 years of work experience at the present organisation

\begin{tabular}{|c|c|c|c|c|c|c|c|}
\hline \multirow{2}{*}{ Variables } & \multirow{2}{*}{$\mathbf{R}$} & \multirow{2}{*}{ Adj $\mathbf{R}^{\mathbf{2}}$} & $\mathbf{t}$ & \multirow{2}{*}{ Reg coeff } & \multicolumn{3}{|c|}{ Change Statistics } \\
\hline A3 & 0.378 & 0.133 & 3.719 & 0.170 & 0.143 & 13.834 & .000 \\
\hline A5 & 0.294 & 0.075 & 2.800 & 0.151 & 0.086 & 7.843 & .006 \\
\hline A7 & 0.350 & 0.122 & 3.402 & 0.205 & 0.122 & 11.572 & .001 \\
\hline A8 & 0.244 & 0.048 & 2.295 & 0.131 & 0.060 & 5.269 & .024 \\
\hline A9 & 0.280 & 0.079 & 2.660 & 0.153 & 0.079 & 7.074 & .009 \\
\hline A10 & 0.299 & 0.089 & 2.855 & 0.221 & 0.089 & 8.152 & .005 \\
\hline
\end{tabular}

The Table.43 presents the regression significance at $p<0.05$ and the respective coefficients of the individual antecedents of $\mathrm{P}$ $\mathrm{O}$ fit for the employees with 11 to 20 years of work experience at the present organisation. For this category of employees, it can be seen that the factors principles congruence, values and norms congruence, need congruence and personal skills congruence have no significant impact.

\section{FINDINGS}

The impact of the various antecedents of P-O fit for the various demographics of employees were analysed. Considering all the employees and their P-O fit factors in MLR, there is a significant influence on all the factors. This may infer that all the factors are important for a good P-O fit. But in the SLR, except principles congruence, all other factors are significant.

While considering only the male employees for SLR, except principles congruence and ability congruence all other factors have a significant impact.

For the female employees in SLR, all the factors except principles congruence have significant impact.

While classifying by age, employees under the age group of 20 to 30 are having a better PO fit when the following factors value congruence, workmate congruence, need congruence, culture congruence, personality congruence, goal congruence and work place congruence have significant impact.

When observing the MLR outcomes of the managerial employees, the factors ability congruence, personal skills congruence, personality congruence and goal congruence were significant. This may be because of the fact that managers may feel that only the above mentioned factors are important for their perception of $\mathrm{P}-\mathrm{O}$ fit. While observing the individual regressions for managerial employees, it becomes clear that only need congruence and personality congruence are significant. However for non-managerial employees all the factors except principles congruence are significant.

For the employees who have post graduate qualification, many of the factors have no significant impact on their perception of $\mathrm{P}$ $\mathrm{O}$ fit.

Similarly other demographic variables such as experience of employees, designation of employees and experience of employees were analysed. The results of the individual SLR are summarized in the below table. The regressions which have significant impact are indicated by a check mark.

Table.44. Summary of SLR Results

\begin{tabular}{|c|c|c|c|c|c|c|c|c|c|c|c|}
\hline Factors & Particulars & A1 & A2 & A3 & A4 & A5 & A6 & A7 & A8 & A9 & A10 \\
\hline \multirow{3}{*}{ Gender } & Male & & $\checkmark$ & $\checkmark$ & $\checkmark$ & $\checkmark$ & $\checkmark$ & $\checkmark$ & $\checkmark$ & $\checkmark$ & $\checkmark$ \\
\hline & Female & & $\checkmark$ & $\checkmark$ & $\checkmark$ & & $\checkmark$ & $\checkmark$ & $\checkmark$ & $\checkmark$ & $\checkmark$ \\
\hline \multirow{4}{*}{ Age } & $20-30$ & & $\checkmark$ & $\checkmark$ & $\checkmark$ & & & $\checkmark$ & $\checkmark$ & $\checkmark$ & $\checkmark$ \\
\hline & $31-40$ & & & $\checkmark$ & $\checkmark$ & $\checkmark$ & $\checkmark$ & $\checkmark$ & $\checkmark$ & $\checkmark$ & $\checkmark$ \\
\hline & 41 and above & & $\checkmark$ & & & & & $\checkmark$ & & & \\
\hline \multirow{3}{*}{ Desig. } & Managers & & & & $\checkmark$ & & & & $\checkmark$ & & \\
\hline & Non Managers & & $\checkmark$ & $\checkmark$ & $\checkmark$ & $\checkmark$ & $\checkmark$ & $\checkmark$ & $\checkmark$ & $\checkmark$ & $\checkmark$ \\
\hline \multirow{5}{*}{ Edu. } & ITI & & & $\checkmark$ & $\checkmark$ & & $\checkmark$ & $\checkmark$ & $\checkmark$ & $\checkmark$ & \\
\hline & Polytechnic & & $\checkmark$ & $\checkmark$ & & & $\checkmark$ & $\checkmark$ & & $\checkmark$ & $\checkmark$ \\
\hline & UG & & & $\checkmark$ & & & & $\checkmark$ & $\checkmark$ & $\checkmark$ & $\checkmark$ \\
\hline & PG & & & & $\checkmark$ & $\checkmark$ & $\checkmark$ & & & & \\
\hline \multirow{3}{*}{ Exp. } & $1-10$ years & & $\checkmark$ & $\checkmark$ & $\checkmark$ & & $\checkmark$ & $\checkmark$ & $\checkmark$ & $\checkmark$ & $\checkmark$ \\
\hline & $11-20$ years & & & $\checkmark$ & & $\checkmark$ & & $\checkmark$ & $\checkmark$ & $\checkmark$ & $\checkmark$ \\
\hline \multirow{3}{*}{} & $11-20$ & & & & & & \\
\hline
\end{tabular}


It was observed that for almost all of the categories of employees, the factor principles congruence has no impact on $\mathrm{P}$ $\mathrm{O}$ fit. This may be because of the fact that employees may feel that a congruence of their personal principles with the organisation's may not be of importance because they may be flexible in this issue when other factors are present in the organisation.

\section{CONCLUSION}

In this study, P-O fit of employees in a watch manufacturing unit were examined and the results indicate that the different categories of employees have different antecedents impacting their P-O fit. All the factors are significant when all the employees are considered together. However when they are classified based on demographics this phenomenon changes. Most of the outcomes of the analysis are supported by literature, while the non-impact of principles congruence will have to be researched in-depth to understand its implications.

\section{REFERENCE}

[1] G.L. Blau, "Using a Person-Environment Fit Model to Predict Job Involvement and Organizational Commitment", Journal of Vocational Behavior, Vol. 30, No. 3, pp. 240-257, 1987.

[2] B.M. Meglino, E.C. Ravlin and C.L. Adkins, "A Work Values Approach to Corporate Culture: A Field Test of the Value Congruence Process and its Relationship to Individual Outcomes", Journal of Applied Psychology, Vol. 74, No. 3, pp. 424-432, 1989.

[3] C.A. Oreilly, J. Chatman and D.F. Caldwell, "People and Organizational Culture: A Profile Comparison Approach to Assessing Person-Organization Fit”, Academy of Management Journal, Vol. 34, No. 3, pp. 487-516, 1991.

[4] Mahmut Demira, Sirvan Sen Demira, and Kevin Nieldb, "The Relationship between Person-Organization Fit, Organizational Identification and Work Outcomes", Journal of Business Economics and Management, Vol. 16, No. 2, pp. 369-386, 2014.

[5] In-Sue Oh et al., "Fit Happens Globally: A Meta-Analytic Comparison of the Relationships of Person-Environment Fit Dimensions with Work Attitudes and Performance across East Asia, Europe, and North America", Personnel Psychology, Vol. 67, No. 1, pp. 99-152, 2014.

[6] Donald P. Moynihan and Sanjay K. Pandey, "The Ties that Bind: Social Networks, Person-Organization Value Fit, and Turnover Intention", Journal of Public Administration Research and Theory, Vol. 18, No. 2, pp. 205-227, 2007.

[7] Brian J. Hoffman, Bethany H. Bynum, Ronald F. Piccolo, and Ashley W. Sutton, "Person-Organization Value Congruence: How Transformational Leaders Influence Work Group Effectiveness", Academy of Management Journal, Vol. 54, No. 4, pp. 779-796, 2011.

[8] Yu-Chen Wei, "Person-organization fit and organizational citizenship Behaviour: Time Perspecive", Journal of Management and Organization, Vol. 19, No. 1, pp. 101-114, 2013.

[9] Jaleh Farzaneh, Ali Dehghanpour Farashah and Mehdi Kazemi, "The Impact of Person-Job Fit and Person-
Organization Fit on OCB”, Personnel Review, Vol. 43, No. 5, pp. 672-691, 2014.

[10] Linda P. Livingstone, Debra L. Nelson and Steve H. Barr, "Person-Environment Fit and Creativity: An Examination of Supply-Value and Demand-Ability Versions of Fit", Journal of Management, Vol. 23, No. 2, pp. 119-146, 1997.

[11] Simone Arbour, Catherine T. Kwantes, Joanna M. Kraft and Cheryl A Boglarsky, "Person-Organization Fit: using Normative Behaviors to Predict Workplace Satisfaction, Stress and Intentions to Stay", Journal of Organizational Culture, Communications and Conflict, Vol. 18, No. 1, pp. 41-64, 2014.

[12] J.B. Vancouver and N.W. Schmitt, "An Exploratory Examination of Person-Organization Fit: Organizational Goal Congruence", Personnel Psychology, Vol. 44, No. 2, pp. 333-352, 1991.

[13] W.H. Mobley, "Employee Turnover: Causes, Consequences and Control", Addison-Wesley, 1982.

[14] Jennifer A. Chatman, "Improving Interactional Organizational Research: A Model of Person-Organization Fit”, Academy of Management Review, Vol. 14, No. 3, pp. 333-349, 1989.

[15] Amy L Kristof, "Person-Organisation Fit: An integrative Review of its Conceptualizations, Measurement and Implications", Personnel Psychology, Vol. 49, No. 1, pp. 149, 1996.

[16] Victor R. Tom, "The Role of Personality and Organizational Images in the Recruiting Process", Organizational Behavior and Human Performance, Vol. 6, No. 5, pp. 573-592, 1971.

[17] Fatma Nur Tugal and Kemal Can Kilic, "PersonOrganization Fit: It's Relationships with Job Attitudes and Behaviors of Turkish Academicians", International Review of Management and Marketing, Vol. 5, No. 4, pp. 195-202, 2015.

[18] Mehtap Findik and Adem Ogut, "An Evaluation About Person-Organization Fit, Job Satisfaction, and Turnover Intention: A Case of Health Institution", Mediterranean Journal of Social Sciences, Vol. 4, No. 11, pp. 434-440, 2013.

[19] B.J. Hoffman and D.J. Woehr, “A Quantitative Review of the Relationship between Person-Organization Fit and Behavioral Outcomes", Journal of Vocational Behavior, Vol. 68, No. 3, pp. 389-399, 2006.

[20] P.M. Muchinsky and C.J. Monahan, "What is PersonEnvironment Congruence? Supplementary Versus Complementary Models of Fit", Journal of Vocational Behavior, Vol. 31, No. 3, pp. 268-277, 1987.

[21] B. Schneider, "The People make the Place", Personnel Psychology, Vol. 40, No. 3, pp. 437-453, 1987.

[22] J.J. Parkington and B. Schneider, "Some Correlates of Experienced Job Stress: A Boundary Role Study", Academy of Management Journal, Vol. 22, No. 2, pp. 270-281, 1979.

[23] J.A. Chatman, "Matching People and Organizations: Selection and Socialization in Public Accounting Firms", Administrative Science Quarterly, Vol. 36, No. 3, pp. 459483, 1991.

[24] W.R. Box, R.Y. Odom, and M.G. Dunn, "Organizational Values and Value Congruency and Their Impact on Satisfaction, Commitment, and Cohesion: An Empirical 
Examination within the Public Sector", Public Personnel Management, Vol. 20, No. 1, pp. 195-205, 1991.

[25] T.A. Judge and R.D. Bretz, "Effects of Work Values on Job Choice Decisions", Journal of Applied Psychology, Vol. 77, No. 3, pp. 261-271, 1992.

[26] A.E.M. Van Vianen, I.E. De Pater and F. Van Dijk, "Work Value Fit and Turnover Intention: Same-Source or Different-Source Fit", Journal of Managerial Psychology, Vol. 22, No. 2, pp. 188-202, 2007.

[27] J.W. Westerman and L.A. Cyr, "An Integrative Analysis of Person-Organization Fit Theories", International Journal of Selection and Assessment, Vol. 12, No. 3, pp. 252-261, 2004.

[28] P. Castka, C.J. Bamber, J.M. Sharp and P. Belohoubek, "Factors Affecting Successful Implementation of High Performance Teams", Team performance Management: An International Journal, Vol. 7, No. 7-8, pp. 123-134, 2001.

[29] Sutarjo, "Ten Ways of Managing Person-Organization Fit (P-O Fit) Effectively: A Literature Study", International
Journal of Business and Social Science, Vol. 2, No. 21, pp. 226-231, 2011.

[30] C.A. Oreilly, J. Chatman and D.F. Caldwell, "People and Organizational Culture: A Profile Comparison Approach to Assessing Person-Organization Fit”, Academy of Management Journal, Vol. 34, No. 3, pp. 487-516, 1991.

[31] Brian J Hoffman and David J. Woehr, "A Quantitative Review of the Relationship between Person-Organization Wt and Behavioral Outcomes", Journal of Vocational Behavior, Vol. 68, pp. 389-399, 2006.

[32] Sango Lee and Enumni Jang, "The Relationships of Person Organization Fit and Person Job fit with Work Attitudes : A Moderating Effect of Person-Supervisor Fit", Journal of Engineering and Applied Sciences, Vol. 12, No. 14, pp. 3767-3778, 2017.

[33] Dorota Merecz-Kot and Aleksandra Andysz, "SocioDemographic Predictors of Person-Organization Fit", International Journal of Occupational Medicine and Environmental Health, Vol. 30, No. 1, pp. 133-149, 2017. 